\title{
Prevalence of Elongated Styloid Process and Eagle Syndrome in East Eagean Population
}

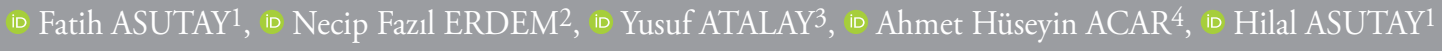

${ }^{1}$ Uzman DentaClinic, Bursa, Turkey

${ }^{2}$ Marmara University Faculty of Medicine, Department of Oral and Maxillofacial Surgery, İstanbul, Turkey

3 Private Vefa Oral and Dental Health Clinic, Afyon, Turkey

4Private Clinic, İstanbul, Turkey

\section{ABSTRACT}

Objective: In this study; we aimed to evaluate the prevalence, clinical and radiographic findings of elongated styloid process (SP) and Eagle syndrome (ES) in Eastern Aegean Turkish population.

Methods: Recordings of 3678 patients over 18 years of age were examined who were admitted to Afyon Kocatepe University Faculty of Dentistry, Department of Oral and Maxillofacial Surgery, between July 1 and December 31, 2014. Length, elongation type, calcification shape, single or double sided appearance of SP and clinical findings were recorded.

Results: In 258 patients (112 male, 146 female), SP were found to be elongated (7.01\%). In 9 patients ( 3 male, 6 female) (0.24\%), symptoms were considered as ES. There was no difference between age, sex and elongated SP ( $\mathrm{p}>0.05)$.

Conclusion: The elongation of the SP may cause a variety of clinical symptoms. This situation may be confused with many other clinical problems. Elongated SP or ES which can be detected in panoramic radiographs should be consulted with the ear-nose-throat clinic.

Keywords: Eagle syndrome, elongated styloid process, prevalence

\section{Introduction}

The styloid process (SP) is a cartilaginous long spine projecting downward from the inferior surface of the temporal bone with an approximate length of $2-3 \mathrm{~cm}$. It is considered elongated when it is longer than $3 \mathrm{~cm}$. Many important neurovascular structures such as the internal jugular vein, internal carotid artery and cranial nerves $(10,11$ and 12$)$ locate near the tip of the SP.

Eagle syndrome (ES) which is also known as styloid-carotid artery syndrome, is a rare condition with an elongation of SP or calcification of stylohyoid ligament and clinical symptoms such as neck and cervicofacial pain (1-7). It was first described by an otorhinolaryngologist, whose name was Eagle, in 1937 (8). Elongated process occurs $4 \%$ of the population and patients are usually asymptomatic and only $4-5 \%$ of them present symptoms with mostly over 30 years of age (9). The elongated SP may be seen as uni- or bilateral and patients may have symptoms related to compression and irritation of cranial nerves (5, 7, 9 and 10) such as dysphagia, tinnitus, otalgia, facial pain while turning the head, foreign body sensation, recurrent orafacial and throat pain, pain on extending tongue and discomfort during chewing (9). It rarely may cause stroke due to the compression of carotid arteries (10). This syndrome is seen most commonly between 30 and 50 years of age. It is more common in women (1:2) according to Bagga et al. (11) and (1:3) according to Alpoz et al. (9). The complaints such as throat pain, unilateral neck pain and tinnitus are classic symptoms of ES. If ES is present, one can palpate the tip of the SP in the back of the throat on the exam, which is normally non-palpable (12). Symptoms may be worsened on

Presented in: Turkish Association of Oral and Maxillofacial Surgery $22^{\text {nd }}$ International Scientific Congress, 
bimanual palpation of the styloid through the tonsillar bed. Patients may be relieved by infiltration of anaesthetic solution into the tonsillar bed. Imaging is important and diagnostic. The enlarged SP may be visible on an orthopantogram or a lateral cephalometry.

There have been several theories on the etiology of the ES but the exact cause is unclear. Local chronic irrigations, endocrine disorders in females at menopause, surgical trauma, mechanical stress, persistence of mesenchymal elements, growth of the osseous tissue or trauma during development of SP could result in calcified hyperplasia of the SP (13-15). Also, women with such elongation may tend to more symptomatic than men according to some studies (16-18).

The aim of this retrospective study is to investigate the prevalence, the clinical symptoms and radiographic location and appearance of the ES in Eastern Aegean Turkish population and its relation with gender and age. The type of elongation and calcification patterns of each elongated SP was classified as elongated, pseudoarticulated and segmented.

\section{Methods}

Recordings of 3678 patients over 18 years of age were examined who admitted to Afyon Kocatepe University Faculty of Dentistry, Department of Oral and Maxillofacial Surgery between July 1 and December 31, 2014 in order to figure out the incidence of ES in Turkish population. There were 1941 males and 1737 females with a mean age of $38.27 \pm 15.81$. All patients included in this study were prescribed digital panoramic radiographs as a part of their diagnostic and treatment work up. There is no exclusion criteria in this study. All the digital panoramic radiographs (PRs) were taken by a Planmeca ProMax X-ray unit (Planmeca, Helsinki, Finland) according to the manufacturer recommendations. Only diagnostically acceptable images were included in the study. The panoramic radiographs were evaluated and the lengths of SP were measured by the same two oral and maxillofacial surgeons. If they did different measurements, they discussed until they agreed with each other. The measurement of the length was initiated proximally at the point where the SP extended from the tympanic plate to the tip of the process (Figure 1). The ossified stylohyoid ligament that joined to SP was added to the measurements. The SPs were divided into 3 groups; elongated, pseudo-articulated and segmented according to radiographic appearance and also recorded as unilateral or bilateral. Length of SP which was longer than $3 \mathrm{~cm}$ was considered as elongated.

Data including atheroma, hypertension, renal problem, osteoporosis, diabetes mellitus, cardiovascular diseases, dysphasia, odynophagia, headache, neckache nausea, sensation of foreign body in throat, pain upon turning head, otalgia and tinnitus were recorded from the patients' medical charts. Patients who experienced recurrent pain in oropharynx and face, dysphagia, foreign body sensation in the throat and one or more of the other symptoms with no other medical reasons but elongated SP were considered as ES.

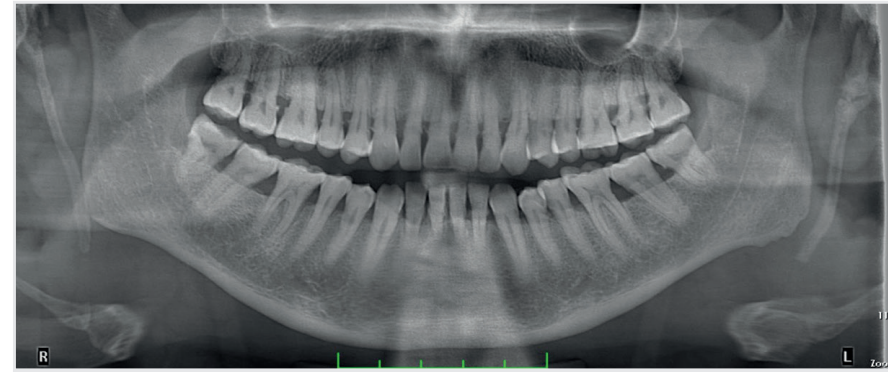

Figure 1. A 64-year old male patient with elongated styloid processes

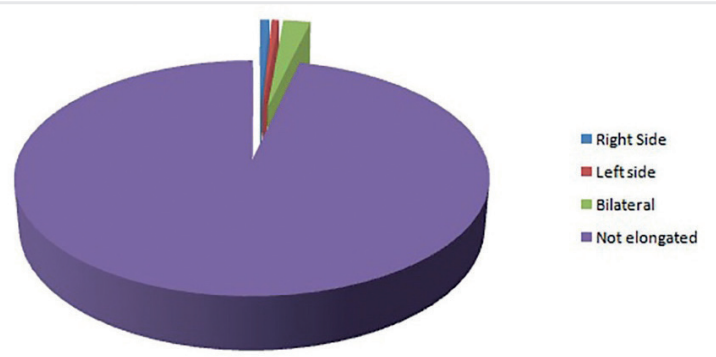

Figure 2. Incidence of styloid process elongation

All procedures followed were in accordance with the ethical standards of the committee responsible for human experimentation (institutional and national) and with the Helsinki Declaration of 1975, as revised in 2008.

\section{Statistical Analysis}

The data were analyzed by using chi-square and Continuity (Yates) Correction.

\section{Results}

In a total of 3678 patients, 258 SP elongation cases (7.01\%) (112 male and 146 female) were determined. Elongation of the SP was recorded right-sided in 28 patients (10.9\%), left sided in 22 patients $(8.5 \%)$ and bilateral in 208 patients $(80.6 \%)$ (Figure 2 ). Number of patients with elongated SP was the highest between the ages of 51-60 and the lowest between the ages of 18-30 in both female and male groups (Table 1). When the relationship between symmetry of the SP elongation and gender was analyzed, we observed symmetry in $84.2 \%$ of the female population and in $75.9 \%$ of the male population.

The types of SP elongation according to gender were listed in Table 2. The elongated type was the most common type both in males (56.3\%) and in females (58.9\%) (Table 2). There were no significant differences between the type of SP elongation and gender, age and radiographic location ( $p>0.05)$.

No statistically significant differences were detected based on atheroma among the genders $(p>0.05)$. The privilege of osteoporosis was significantly higher in females $(12.3 \%)$ compared to males $(3.6 \%)$ which is statistically significant $(\mathrm{p}=0.023 ; \mathrm{p}<0.05)$. Other clinical and systemic symptoms of ES as listed in Table 3 did not show any statistical difference among genders. 


\begin{tabular}{|c|c|c|c|c|}
\hline & Male $(n=112)$ & Female $(n=146)$ & Total & $\mathrm{p}$ \\
\hline \multicolumn{5}{|l|}{ Age } \\
\hline $18-30$ & $14(12.5 \%)$ & $14(9.5 \%)$ & $28(10.9 \%)$ & \multirow{6}{*}{0.500} \\
\hline $31-40$ & $22(19.6 \%)$ & 29 (19.8\%) & $51(19.7 \%)$ & \\
\hline $41-50$ & $23(20.5 \%)$ & $35(24 \%)$ & $58(22.5 \%)$ & \\
\hline $51-60$ & $27(24.2 \%)$ & 47 (32.3\%) & $74(28.7 \%)$ & \\
\hline+60 & $26(23.2 \%)$ & $21(14.4 \%)$ & $47(18.2 \%)$ & \\
\hline Total & 112 & 146 & 258 & \\
\hline \multicolumn{5}{|c|}{ Radiographic location } \\
\hline Right & $17(15.2 \%)$ & $11(7.5 \%)$ & $28(10.9 \%)$ & \multirow{3}{*}{0.135} \\
\hline Left & $10(8.9 \%)$ & $12(8.2 \%)$ & $22(8.5 \%)$ & \\
\hline Bilateral & 85 (75.9\%) & $123(84.2 \%)$ & $208(80.6 \%)$ & \\
\hline Total & 112 & 146 & 258 & - \\
\hline
\end{tabular}

Table 2. Statistical analysis of the types of styloid process

\begin{tabular}{|c|c|c|c|c|}
\hline & $\begin{array}{l}\text { Male } \\
(n=112)\end{array}$ & $\begin{array}{l}\text { Female } \\
(n=146)\end{array}$ & Total & $\mathrm{p}$ \\
\hline \multicolumn{5}{|c|}{ Radiographic appearance } \\
\hline Elongated & $126(56.3 \%)$ & $172(58.9 \%)$ & $298(57.2 \%)$ & 0.545 \\
\hline Pseudoarticulated & $43(19.2 \%)$ & $59(20.2 \%)$ & $102(19.8 \%)$ & 0.775 \\
\hline Segmented & $28(12.5 \%)$ & $38(13 \%)$ & $66(12.8 \%)$ & 0.863 \\
\hline Total & 197 & 269 & 466 & - \\
\hline
\end{tabular}

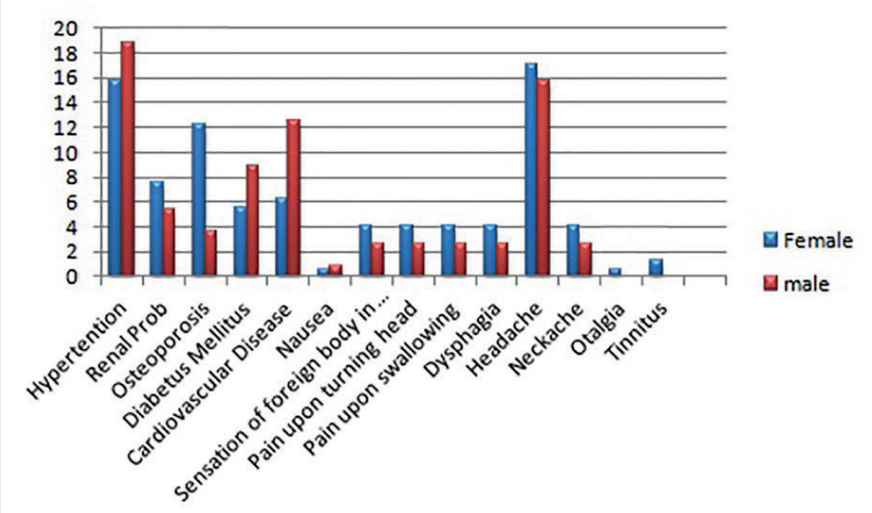

Figure 3. The percentage of systemic and clinical complaints of the patients with styloid process elongation

In this study we found out that headache (18.7\%), hypertension (17.1\%), cardiovascular disease $(8.9 \%)$, osteoporosis $(8.5 \%)$ and renal problem $(6.6 \%)$ were the most common systemic and clinical symptoms that were seen with SP elongation (Figure 3).

\section{Discussion}

Although etiopathogenesis is not clear, mineralization and ossification of the tip of the SP may cause the ES. Local chronic irritations, surgical trauma, endocrine disorders in women at
Table 3. Statistical analysis of systemic and clinical complaints of the patients with styloid process elongation

$\begin{array}{llll}\text { Male } & \text { Female } & \text { Total } & p\end{array}$

\begin{tabular}{|l|l|l|l|l|}
\hline Atheroma & & & \\
\hline Absence & $101(90.2 \%)$ & $132(90.4 \%)$ & $233(90.3 \%)$ & 1.000 \\
\hline Presence & $11(9.8 \%)$ & $14(9.6 \%)$ & $25(9.7 \%)$ & \\
\hline Total & 112 & 146 & 258 & \\
\hline
\end{tabular}

Systemic and clinic situations

\begin{tabular}{|c|c|c|c|c|}
\hline Hipertansion & $21(18.8 \%)$ & $23(15.8 \%)$ & $44(17.1 \%)$ & 0.640 \\
\hline Renal problems & $6(5.4 \%)$ & $11(7.5 \%)$ & $17(6.6 \%)$ & 0.656 \\
\hline Osteoporosis & $4(3.6 \%)$ & $18(12.3 \%)$ & 22 (8.5\%) & $0.023 *$ \\
\hline $\begin{array}{l}\text { Diabetus } \\
\text { mellitus }\end{array}$ & $10(8.9 \%)$ & $8(5.5 \%)$ & $18(7 \%)$ & 0.406 \\
\hline $\begin{array}{l}\text { Cardiovascular } \\
\text { disease }\end{array}$ & 14 (12.5\%) & $9(6.2 \%)$ & $23(8.9 \%)$ & 0.121 \\
\hline Nausea & $1(0.8 \%)$ & $1(0.6 \%)$ & $2(0.7 \%)$ & 1.000 \\
\hline $\begin{array}{l}\text { Sensation of } \\
\text { foreign body in } \\
\text { throat }\end{array}$ & $3(2.6 \%)$ & $6(4.1 \%)$ & $9(3.4 \%)$ & 0.317 \\
\hline $\begin{array}{l}\text { Pain upon } \\
\text { turning head }\end{array}$ & $3(2.6 \%)$ & $6(4.1 \%)$ & $9(3.4 \%)$ & 0.317 \\
\hline $\begin{array}{l}\text { Pain upon } \\
\text { swallowing }\end{array}$ & $3(2.6 \%)$ & $6(4.1 \%)$ & $9(3.4 \%)$ & 0.317 \\
\hline Dysphagia & $3(2.6 \%)$ & $6(4.1 \%)$ & $9(0.3 \%)$ & 0.317 \\
\hline Headache & 23 (15.8\%) & 25 (17.1\%) & 48 (18.7\%) & 0.624 \\
\hline Neckache & $3(2.6 \%)$ & $6(4.1 \%)$ & 9 (3.4\%) & 0.317 \\
\hline Otalgia & 0 & $1(0.6 \%)$ & $1(0.3 \%)$ & 1.000 \\
\hline Tinnitus & 0 & $2(1.3 \%)$ & $2(0.7 \%)$ & 1.000 \\
\hline
\end{tabular}

menopause, persistence of mesenchymal elements and trauma or mechanical stress during development are suspected to cause elongation of SP $(8,10,19)$. The stylohyoid ligament is normally composed of dense fibrous connective tissue and has the potential to become partially or completely ossified (9). The resultant abnormal styloid chain may compress or irritate nearby anatomical structures and cause the clinical symptoms of ES. Anatomically, the apex of the SP is located between internal and external carotid arteries. It is also related with the facial nerve, anteromedially and accessory and vagus nerve, medially. Clinicians mostly fail to diagnose the SP elongation. Thus, elongation of the SP should be considered for the diagnosis and treatment of head and neck pain.

Cervical myofacial pain syndrome, migraine, trigeminal neuralgia, nasopharyngeal lesions, tonsillitis, otitis, neck pain, psychosomatic diseases, nervus intermedius neuralgia, atherosclerosis, dental pains, glossopharyngeal neuralgia and temporomandibular joint disorders should be considered in differential diagnosis $(1,11,20)$. Therefore, a detailed differential diagnosis for SP elongation should be performed. The incidence of the elongated SP ranges between $1.4 \%$ and $30 \%$ in the literature $(1,8,9,11)$ however, only between $1 \%$ and $5 \%$ of the patients were reported to be actually symptomatic (9). The pathophysiology of the pain related to elongated SP was thought 
to be due to the compression of the nerves such as the lower branch of the trigeminal nerve, glossopharyngeal nerve and/or the chorda tympani. The threshold for elongation is variable in the literature but $30 \mathrm{~mm}$ was considered as the threshold by many publications $(5,21-23)$.

$\mathrm{PR}$ is mostly used to determine whether the SP is elongated (24). Anbiaee and Javadzadeh (24) used PR for the measurement of SP length and indicated that its length was associated with increasing age, however, in this study we could not find statistically significant correlation between the incidence of SP elongation and age. We used Langlai's classification of elongated SP which is based on three types of complexes; type 1, elongated; type 2, pseudoarticulated; and type 3, segmented. In this study only $7.01 \%$ of the studied population was diagnosed as having SP elongation with the most prevalent pattern of elongated type which is in agreement with the previous studies (9). We observed symmetry for the pattern of elongated SP in $84.2 \%$ of the female population and in $75.9 \%$ of the male population which is in accordance with the literature $(25,26)$. Gender had no statistically significant influence on the type of SP elongations which is also consistent with the literature $(18,25)$.

Headache was the most common clinical symptom in the patients with elongated SP according to this study. Only 9 of the 258 patients with elongated SP declared dysphagia and foreign body sensation in the throat which are the most commonly seen symptoms of ES. Fourty eight of them were complaining from headache whereas only 9 of them reported neckache. Thus we evaluated only 9 ( 6 female and 3 male) of the 258 patients with elongated SP as true ES. During the clinical examinations of these 9 patients, SPs were easily palpated intraorally. Only 5 (4 female and 1 male) of the patients with ES underwent surgery and other 4 of them did not want to be operated. The reason of high headache privilege could be due to the hypertension and other stress factors.

\section{Study Limitations}

Further studies are needed to clarify the clinical significance between PR and ES. Another limitation of the present study is the relatively small number of subjects.

\section{Conclusion}

Based on this retrospective study, the privilege of elongated SP is 7\% in Eastern Eagean Turkish population and only 3.5\% of them are actually symptomatic.

\section{Acknowledgments}

The authors declared that this study has received no financial support and no potential conflicts of interest with respect to the authorship and/or publication of this article.

\section{Ethics}

Ethics Committee Approval: Not applicable.

Informed Consent: Not applicable.

Peer-review: Externally peer-reviewed.

\section{Authorship Contributions}

Concept: F.A., Design: F.A., N.F.E., Y.A., Data Collection or Processing: F.A., Y.A., H.A., Analysis or Interpretation: F.A., H.A., A.H.A., Literature Search: F.A., N.F.E., Y.A., Writing: F.A., N.F.E.

Conflict of Interest: No conflict of interest was declared by the authors.

Financial Disclosure: The authors declared that this study received no financial support.

\section{References}

1. Gokce C, Sisman Y, Sipahioglu M. Styloid Process Elongation or Eagle's Syndrome: Is There Any Role for Ectopic Calcification? Eur J Dent 2008;2:224-8.

2. Krennmair G, Piehslinger E. Variants of ossification in the stylohyoid chain. Cranio 2003;21:31-7.

3. Neville BW, Damm DD, Allen CM, Bouquot JE. Developmental defects of the oral and maxillofacial region. In: Neville BW, Damm DD, Allen CM, Bouquot JE, eds. Oral and maxillofacial pathology. Philadelphia: W.B. Saunders company, 1996:1-43.

4. Gözil R, Yener N, Calgüner E, Araç M, Tunç E, Bahcelioğlu M. Morphological characteristics of styloid process evaluated by computerized axial tomography. Ann Anat 2001;183:527-35.

5. Ilgüy M, Ilgüy D, Güler N, Bayirli G. Incidence of the type and calcification patterns in patients with elongated styloid process. J Int Med Res 2005;33:96-102.

6. Kursoglu P, Unalan F, Erdem T. Radiological evaluation of the styloid process in young adults resident in Turkey's Yeditepe University faculty of dentistry. Oral Surg Oral Med Oral Pathol Oral Radiol Oral Endod 2005;100:491-4.

7. Murtagh RD, Caracciolo JT, Fernandez G. CT findings associated with Eagle syndrome. Am J Neuroradiol 2001;22:1401-2.

8. Reddy RS, Kiran CS, Madhavi NS, Raghavendra MN, Satish A. Prevalence of elongation and calcification patterns of elongated styloid process in south India J Clin Exp Dent 2013;5:e30-5.

9. Alpoz E, Akar GC, Celik S, Govsa F, Lomcali G. Prevalence and pattern of stylohyoid chain complex patterns detected by panoramic radiographs among Turkish population Surg Radiol Anat 2014;36:3946.

10. Watanabe PC, Dias FC, Issa JP, Monteiro SA, Paula FJ, Tiossi R. Elongated styloid process and atheroma in panoramic radiography and its relationship with systemic osteoporosis and osteopenia. Osteoporos Int 2010;21:831-6.

11. Bagga MB, Kumar CA, Yeluri G. Clinicoradiologic evaluation of styloid process calcification. Imaging Sci Dent 2012;42:155-61.

12. Scheller K, Eckert AW, Scheller C. Transoral, retromolar, paratonsillar approach to the styloid process in 6 patients with Eagle's syndrome. Med Oral Patol Oral Cir Bucal 2014;19:e61-6.

13. Park JH, Omi N, Nosaka T, Kitajima A, Ezawa I. Estrogen deficiency and low-calcium diet increased bone loss and urinary calcium excretion but did not alter arterial stiffness in young female rats. J Bone Miner Metab 2008;26:218-25. 
14. Rizzatti-Barbosa CM, Di Hipolito O Jr, Di Hipolito V, AlbergariaBarbosa JR. Prevalence of stylohyoid ligament complex elongation in a Brazilian edentulous adult population. Rev Assoc Odont Argent 2003;91:231-5.

15. Rizzatti-Barbosa CM, Ribeiro MC, Silva-Concilio LR, Di Hipolito O, Ambrosano GM. Is an elongated stylohyoid process prevalent in the elderly? A radiographic study in a Brazilian population. Gerodontology 2005;22:112-5.

16. Keur JJ, Campbell JPS, McCarthy JF, Ralph WJ. The clinical significance of the elongated styloid process. Oral Surg 1986;61:399404.

17. Koivumäki A, Marinescu-Gava M, Järnstedt J, Sándor GK, Wolff J. Trauma induced eagle syndrome. Int J Oral Maxillofac Surg 2012;41:350-3.

18. Okabe S, Morimoto Y, Ansai T, Yamada K, Tanaka T, Awano S, et al. Clinical significance and variation of the advanced calcified stylohyoid complex detected by panoramic radiographs among 80-year-old subjects. Dentomaxillofac Radiol 2006;5:191-9.

19. Rizzatti-Barbosa CM, Ribeiro MC, Silva-Concilio LR, Hipolito OD, Ambrosano GM. Is an elongated stylohyoid process prevalent in the elderly? A radiographic study in a Brazilian population. Gerodontology 2005;22;112-5.
20. Andrade KM, Rodrigues CA, Watanabe PC, Mazzetto MO. Styloid Process Elongation and Calcification in Subjects with TMD: Clinical and Radiographic Aspects. Braz Dent J 2012;23:443-50.

21. Anbiaee N, Javadzadeh A. Elongated styloid process: is it a pathologic condition? Indian J Dent Res 2011;22:673-7.

22. Rizzatti-Barbosa CM, Ribeiro MC, Silva-Concilio LR, Di Hipolito O, Ambrosano GM. Is an elongated stylohyoid process prevalent in the elderly? A radiographic study in a Brazilian population. Gerodontology 2005;22:112-5.

23. ScafG, Freitas DQ, Monteiro Loffredo LC. Diagnostic reproducibility of the elongated styloid process. J Appl Oral Sci 2003;11:120-4.

24. Anbiaee N, Javadzadeh A. Elongated styloid process: Is it a pathologic condition? Indian Journal of Dental Research 2011;22:673-7.

25. MacDonald-Jankowski DS. Calcification of the stylohyoid complex in Londoners and Hong Kong Chinese. Dentomaxillofac Radiol 2001;30:35-9.

26. Oztas B, Orhan K. Investigation of the incidence of stylohyoid ligament calcifications with panoramic radiographs. J Investig Clin Dent 2012;3:30-5. 